\title{
Konstruksi sosial: Aktivitas belajar siswa SMP Negeri 10 Malang korban school bullying pada kelas VII
}

\author{
Nelly Isroy Camelya, I Nyoman Ruja*, Sukamto, I Dewa Putu Eskasasnanda \\ Universitas Negeri Malang, Jl. Semarang No. 5 Malang, Jawa Timur, Indonesia \\ *Penulis korespondensi, Surel: nyoman.ruja.fis@um.ac.id
}

Paper received: 03-02-2021; revised: 15-02-2021; accepted: 28-02-2021

\begin{abstract}
This study aims to describe the characteristics of students victims of school bullying grade VII, (2) forms of school bullying, (3) social construction causes school bullying, (4) learning activities of students victims of school bullying, (5) social construction of teachers in providing social intervention and construction to school bullying. The research was conducted at SMP Negeri 10 Malang using qualitative approach with case study type research. The results showed that: first, victims of bullying in grade VII are different from students in general both physically and academically, victims of bullying have hurt their feelings and do not have many friends. Second, this form of bullying consists of physical, verbal, mental/psychological and electronic. Third, acts of bullying cannot be released from social construction because perpetrators, spectators and teachers justify bullying occurring because of the victim's fault. Fourth, bullying can make victims have learning difficulties. Fifth, the intervention taken by the teacher is to provide material about bullying, make the classroom atmosphere comfortable and make a picture about the prohibition of bully.
\end{abstract}

Keywords: social construction; school bullying victims; learning activities

\begin{abstract}
Abstrak
Penelitian ini bertujuan untuk mendeskripsikan mengenai: (1) karakteristik siswa korban school bullying kelas VII, (2) bentuk-bentuk school bullying, (3) konstruksi sosial penyebab school bullying, (4) aktivitas belajar siswa korban school bullying, (5) konstruksi sosial guru dalam memberikan intervensi dan konstruksi sosial terhadap school bullying. Penelitian dilakukan di SMP Negeri 10 Malang dengan menggunakan pendekatan kualitatif dengan jenis penelitian studi kasus. Hasil penelitian menunjukkan bahwa: pertama, korban bullying di kelas VII berbeda dengan siswa pada umumnya baik secara fisik maupun akademik, korban bullying pernah menyakiti perasaan temannya dan tidak memiliki teman yang banyak. Kedua, bentuk bullying terdiri dari fisik, verbal, mental/psikologis dan elektronik. Ketiga, tindakan bullying tidak dapat dilepaskan dari konstruksi sosial karena pelaku, penonton dan guru membenarkan bullying terjadi karena kesalahan korban. Keempat, bullying dapat membuat korban mengalami kesulitan belajar. Kelima, tindakan intervensi yang dilakukan guru adalah memberikan materi mengenai bullying, membuat suasana kelas nyaman dan membuat gambar tentang larangan mem-bully.
\end{abstract}

Kata Kunci: konstruksi sosial; korban school bullying, aktivitas belajar

\section{Pendahuluan}

Pendidikan merupakan pondasi tercapainya suatu bangsa yang lebih baik, karena dengan pendidikan dapat dihasilkan manusia mampu bersaing berkualitas, dan memiliki budi pekerti yang luhur. Salah satu tempat untuk menempuh pendidikan yaitu di sekolah. Menurut (Kamus Besar Bahasa Indonesia (KBBI), Online (http://kbbi.web.id/).) bangunan atau lembaga untuk pelaksanaan belajar dan mengajar serta sebagai tempat menerima dan memberi pelajaran disebut dengan sekolah. 
Pelaksanaan pendidikan di sekolah membutuhkan beberapa faktor pendukung, salah satunya adalah keadaan kelas yang kondusif secara non fisik. Hal ini diwujudkan melalui suasana kelas yang damai. (Wiyani, 2012) menyatakan sekolah yang bebas dari pertikaian, memiliki ketentraman, kekerasan, aman, dan nyaman, memberikan perhatian, kasih sayang, akomodatif, mampu bekerja sama, ketaatan terhadap peraturan, mampu menginternalisasikan nilai-nilai dalam agama dan berhubungan baik dengan masyarakat sekitar merupakan 9 kategori sekolah damai.

Banyak sekolah di Indonesia saat ini belum mampu mewujudkan kelas yang kondusif secara non fisik kepada siswanya. Penelitian dari Yayasan Semai Jiwa Amini atau disingkat dengan (SEJIWA, 2008) menunjukkan bahwa setiap sekolah di Indonesia tidak ada yang bebas dari tindakan kekerasan. Salah satu bentuk kekerasan yang dapat menghambat terwujudnya ketercapaian pembelajaran adalah penggertakan pada anak (bullying). (Olweus, 2003) berpendapat bahwa: "bullying behaviors include direct physical and verbal aggression, as well as indirect or relational aggression and can take place in both offline and online contexts". Artinya bullying merupakan tindakan berupa kekerasan fisik, penyerangan secara verbal, penyerangan secara tidak langsung dan dapat juga terjadi melalui dunia maya.

Salah satu sekolah yang diketahui terdapat tindakan bullying adalah SMP Negeri 10 Malang. Hal ini berdasarkan pengalaman peneliti ketika melakukan Kajian dan Praktik Lapangan (KPL) di sekolah tersebut. Contoh kasus yang terjadi adalah bullying secara fisik dan verbal pada salah satu siswa yang mengalami kelainan fisik. Hal ini berakibat pada korban yang merasa tertekan sehingga terganggu dalam melaksanakan aktivitas belajarnya.

\section{Metode}

Pendekatan kualitatif dengan jenis penelitian studi kasus digunakan dalam penelitian ini. Kehadiran peneliti dalam proses penelitian penting dikarenakan peneliti berperan sebagai instrumen dan pengumpul data. SMP Negeri 10 Malang dipilih sebagai lokasi penelitian karena merupakan tempat KPL peneiliti. Hal ini membuat peneliti mengetahui bahwa di sekolah tersebut terdapat tindakan bullying. Korban school bullying merupakan informan kunci, sedangkan informan pendukung adalah kepala sekolah, guru, teman peneliti yang menjadi alumni di SMP Negeri 10 Malang, teman peneliti yang pernah melakukan KPL di kelas VII, cleaning service, pelaku bullying dan penonton bullying. Teknik pengumpulan data menggunakan observasi non partisipan, dokumentasi dan wawancara mendalam. Teknik analisis data yang digunakan adalah model interaktif (Miles, Mettew B. \& Huberman, A., Michael, 1992) yang terdiri dari pengumpulan data, reduksi data, penyajian data, dan penarikan kesimpulan. Pengecekan keabsahan data dilakukan dengan triangulasi (sumber, teknik dan waktu), ketekunan, keajegan pengamatan, dan kecukupan bahan referensi. Tahapan penelitian yang dilakukan yaitu, tahap pra-lapangan, tahap pekerjaan lapangan dan tahap pasca lapangan.

\section{Hasil dan Pembahasan}

\subsection{Karakteristik Korban School Bullying Kelas VII di SMP Negeri 10 Malang}

Tindakan bullying di SMP Negeri 10 Malang paling banyak terjadi di kelas VII. Fakta ini sesuai dengan pendapat Rigby (2003:2) bahwa bullying meningkat pada awal SMP atau secondary school. Hal ini dikarenakan siswa kelas VII sedang dalam proses adaptasi dengan 
teman barunya. Menurut Gerungan (1991:55) adaptasi merupakan suatu proses penyesuaian pribadi terhadap lingkungan yang baru.

Siswa harus bisa menyeimbangkan antara tuntutan yang berasal dari dalam dirinya dengan tuntutan dari lingkungan salah satunya teman, agar tercapai keberhasilan dalam beradaptasi dengan lingkungan barunya. Apabila siswa tidak dapat menyelaraskan tuntutan dari temannya, maka akan terjadi konflik antar teman sebaya. Hal ini sesuai dengan pendapat (Aryanto, 1992) bahwa resiko tertinggi dalam mengalami konflik dengan teman sebaya adalah saat usia remaja hal ini karena beberapa alasan, antara lain (1) situasi yang kompetitif di sekolahnya, baik yang berhubungan dengan pelajaran atau hubungan sosial; dan (2) perbedaan latar belakang sosial dan budaya.

Berdasarkan hasil penelitian, siswa kelas VII di SMP Negeri 10 Malang yang menjadi korban bullying berusia 13 tahun. (Mappiare, 1982) menjelaskan ciri khas remaja awal antara lain adalah memiliki emosi yang tidak stabil saat berhadapan dengan orang disekitarnya, keadaan semacam ini diistilahkan sebagai masa badai dan tekanan (storm and stress). Artinya bahwa, masa remaja merupakan masa pencarian jati diri yang sering menyebabkan individu menjadi labil serta penuh tekanan dari teman sebaya.

Siswa yang menjadi korban bullying di kelas VII SMP Negeri 10 Malang memiliki karakteristik yang berbeda dengan siswa lainnya. Hasil wawancara dengan informan menunjukkan bahwa korban bullying merupakan siswa yang pendiam dan hanya memiliki sedikit teman karena kurang bergaul. Korban bullying yang memiliki kekurangan fisik juga dapat dianggap berbeda oleh teman-temannya. Hal ini sesuai dengan pernyataan Rigby (2003:4) yang menyatakan bahwa:

Although any child may become a victim of bullying, children are morelikely to be bullied if they are physically weak, introverted, timid, anxious and unassertive, or if they belong to a group againts which there is such prejudice that they can be isolated. This could include belonging to a racial or religious minority or being disabled.

Artinya korban bullying dapat dialami oleh setiap anak yang memiliki kemungkinan jika diganggu mereka secara fisik lemah, sifatnya pemalu, cenderung tertutup, mudah cemas dan tidak bisa tegas atau jika mereka termasuk kelompok yang dicurigai sehingga mereka diisolasi. Hal ini juga berhubungan dengan minoritas ras atau agama serta yang memiliki keterbatasan fisik.

Korban bullying di kelas VII SMP Negeri 10 Malang merupakan siswa yang memiliki sikap menyebalkan, sehingga menyebabkan teman-temannya menjauhi korban. Siswa dengan kelemahan akademik juga sering menjadi korban bullying. Meskipun demikian, siswa yang memiliki kelebihan di bidang akademik juga menjadi alasan untuk di-bully. Hal ini sesuai dengan pernyataan Coloroso (2007: 95-96) bahwa siswa yang dijadikan target bullying kurang memiliki keterampilan verbal dan juga memiliki perilaku yang dianggap mengganggu bagi orang lain. Korban bullying yang memiliki kelebihan seperti cerdas dan berbakat juga dijadikan sasaran karena unggul atau berbeda dengan lainnya. 


\subsection{Bentuk-Bentuk School Bullying}

Bentuk bullying yang terjadi di kelas VII SMP Negeri 10 Malang adalah verbal, fisik, mental/psikologis dan elektronik (cyber bullying). Berdasarkan hasil penelitian, bullying verbal merupakan bentuk bullying yang paling sering terjadi di kelas VII, karena hanya berupa kata-kata sehingga sangat mudah dilakukan oleh siswa, baik laki-laki maupun perempuan. Hal ini sesuai dengan pernyataan SEJIWA (2008:3-4) bahwa bullying verbal merupakan bentuk bullying yang menyakitkan, mudah dilakukan dan dapat terdeteksi karena bisa tertangkap indera pendengaran.

Selama ini bullying verbal dianggap biasa karena hanya berupa ejekan, namun hasil penelitian menunjukkan bahwa bullying verbal memiliki dampak buruk karena sifatnya yang tersembunyi dan dapat melukai aspek mental/psikologis korban. Contohnya adalah memanggil nama orang tua yang sudah meninggal, hal ini membuat korban merasa sedih dan tertekan karena teringat orang tuanya yang sudah meninggal. SEJIWA (2008:4) menyatakan bahwa bullying mental/psikologis adalah bentuk bullying yang membahayakan karena terjadi diam-diam dan di luar pemantauan orang dewasa.

Seiring dengan perkembangan zaman, bullying verbal ternyata tidak hanya dapat dilakukan melalui lisan saja, namun bisa dilakukan melalui alat elektronik. Hasil penelitian menunjukkan bahwa ada salah satu pelaku yang memanfaatkan telepon untuk meneror korbannya. Hal ini sesuai dengan pendapat (Tisna, 2010) bahwa bullying elektronik merupakan tindakan melalui internet dan teknologi digital seperti ponsel, MMS, SMS, email, website, instant messenger, blog, online forum, dan situs jejaring sosial. Tujuannya adalah untuk mempermalukan, mengganggu, merusak reputasi korban bullying dan mengucilkan.

Tidak hanya bullying verbal dan mental/psikologis yang terjadi di kelas VII SMP Negeri 10 Malang, namun ada pula bentuk bullying secara fisik. Adapun bentuk bullying fisik berupa pelecehan seksual secara fisik seperti memegang area sensitif yang dilakukan oleh laki-laki maupun perempuan. (Lahey, 2009) menyatakan penyimpangan seksual tentu hal yang tidak wajar karena melibatkan hal yang nyata dan penting, selain itu mengandung kekerasan pada korbannya dan mengancam merupakan salah satu bentuk lain dari perilaku pelecehan seksual.

\subsection{Konstruksi Sosial Penyebab School Bullying}

Tindakan school bullying di kelas VII SMP Negeri 10 Malang tidak dapat dilepaskan dari teori konstruksi sosial. Menurut Berger dan Luckman (1990:24) konstruksi sosial merupakan bagian yang saling terkait dari tiga momen dialektis yaitu (1) Usaha manusia dalam menunjukkan ekspresi diri kepada dunia, baik dalam kegiatan fisik maupun mental disebut dengan eksternalisasi. (2) Hasil yang telah dicapai, baik mental maupun fisik dari kegiatan eksternalisasi disebut dengan Objektivasi. (3) Penyerapan kembali dunia objektif ke dalam kesadaran sedemikian rupa sehingga subjektif individu dipengaruhi oleh struktur dunia social disebut Internalisasi.

Peran teori ini sesuai dengan hasil penelitian di lapangan. Berdasarkan hasil penelitian diketahui bahwa pelaku, penonton dan guru membenarkan bullying terjadi akibat kesalahan korban sendiri. Kesalahan korban ini termasuk dalam momen eksternalisasi yang artinya korban akan mendapatkan bullying karena perlakuannya sendiri. Korban akan merasa terpojok dan tidak dapat membela dirinya sendiri, sehingga dia menerima perlakuan bullying, 
hal ini termasuk dalam momen objektivasi. Momen selanjutnya yaitu internalisasi yang merupakan kesadaran korban, bahwa perlakuan bullying tidak hanya dilakukan oleh satu siswa, melainkan hampir semua siswa, bahkan guru juga ikut melakukannya. Menurut Septrina \& Liow (2009:101) bahwa tindakan bullying dapat dihindari jika korban memiliki harga diri yang tinggi, sehingga dia dapat menghindarkan diri dari dampak tindakan bullying.

Korban yang di-bully enggan menceritakan permasalahannya pada guru dan orang tua karena mereka menganggap bahwa yang salah bukan pelaku bullying melainkan dirinya sendiri. Alasan lain korban tidak melapor pada guru karena korban takut memperoleh perlakuan yang lebih parah dari sebelumnya. Menurut (SEJIWA, 2008) jika korban melapor pada guru, maka guru akan menindaklanjuti pelaku bullying, kemudian pelaku akan kembali beraksi pada korban dan memberikan perlakuan dan siksaan yang lebih keras.

Berdasarkan hasil penelitian, para pelaku juga melakukan bullying untuk balas dendam pada korban karena telah melakukan bullying terlebih dahulu. (Riauskina, I.I., Djuwita, R., dan Soesetio, S.R., 2005) menyatakan bahwa bullying merupakan sebuah siklus, yang artinya pelaku bullying kemungkinan besar pernah menjadi korban bullying. Para penonton bullying juga menganggap bahwa korban layak di-bully karena telah berbuat salah. Hal ini menyebabkan penonton hanya mendiamkan perlakuan bullying. Para penonton bullying tidak mau membela korban karena takut dirinya ikut menjadi korban bullying. (Coloroso, 2007) menyatakan bahwa menolong korban akan kehilangan reputasi mereka.

Guru juga membenarkan bahwa bullying terjadi karena korban telah melakukan kesalahan, sehingga tidak semua guru membela korban bullying. Beberapa guru sering memarahi korban di hadapan siswa yang lain, sehingga memicu pelaku untuk melakukan tindakan bullying. Hal ini sesuai dengan pernyataan (Ehan, 2012) bahwa lingkungan sekolah bisa menjadi faktor penyebab siswa melakukan bullying, misalnya perbuatan kasar guru kepada siswa, kondisi siswa baik dalam sosial ekonomi maupun dalam prestasi dan perilaku siswa kurang diperhatikan oleh guru.

Berdasarkan fakta di atas, diketahui bahwa bullying terjadi karena korban tidak memiliki kesamaan karakter dengan teman-temannya, sehingga dianggap salah oleh para pelaku, penonton dan juga guru. Hal ini sesuai dengan pernyataan (Mappiare, 1982) bahwa bagi remaja yang bersekolah, dalam masa remaja awal umumnya siswa memilih teman karena pola tingkah laku, minat/kesenangan, kepribadian, ciri-ciri fisik, dan nilai-nilai yang dianut. Oleh karena itu, pemilihan teman dapat dilihat dari keserasian dan kesamaan.

\subsection{Konstruksi Sosial: Aktivitas Belajar Siswa Korban School Bullying}

Tindakan school bullying yang terjadi di kelas VII SMP Negeri 10 Malang berdampak negatif bagi korbannya. Hal ini sesuai dengan pendapat Mudjijanti (2011:3) bahwa bullying memiliki lebih banyak dampak negatif daripada positif bagi perkembangan karakter siswa khususnya korban bullying. Akibat adanya bullying akan mempengaruhi mental dan kesehatan fisik, sehingga dapat mempersulit aktivitas belajar korban bullying. Menurut Idrus \& Ishak (2012:19) aktivitas belajar merupakan kegiatan jiwa raga yang dilakukan seseorang untuk memperoleh perubahan pada dirinya seutuhnya.

Hasil penelitian menunjukkan dampak negatif bullying yang paling sering dialami korban adalah kesulitan dalam menjalani aktivitas belajar, baik di sekolah maupun di luar 
sekolah. Hal ini terjadi karena mental korban yang terganggu, sehingga korban merasa ketakutan yang berlebih pada pelaku, tidak memiliki kepercayaan diri yang tinggi saat berada di kelas dan sering mencari alasan untuk menghindari bullying. Akibatnya korban tidak dapat konsentrasi dengan baik dalam proses pembelajaran. Hal ini didukung oleh pendapat (Wiyani, 2012) bahwa korban bullying akan mengalami kendala dalam mengikuti pembelajaran, takut untuk pergi ke sekolah, prestasi di bidang akademik akan menurun dan adanya ketidakmauan mengikuti kegiatan yang biasanya disukai.

Bullying juga mempengaruhi kesehatan fisik korban, seperti sakit panas, sakit perut, nyeri, memar di badan, tidak nafsu makan dan susah tidur. Hal ini membuat aktivitas belajar korban juga terganggu. (Astuti, 2008) menyatakan dampak negatif bullying adalah korban akan sakit panas, pusing dan sakit perut terutama di pagi hari menjelang berangkat sekolah. Pada kondisi selanjutnya korban bullying sering mengasingkan diri dari sekolah, timbul perasaan tertekan, harga diri yang rendah, malu, trauma, merasa sendiri, menderita ketakutan sosial, terlihat cemas, sedih dan depresi.

Berdasarkan hasil penelitian, peran teori konstruksi sosial mengenai aktivitas belajar korban bullying terdiri dari eksternalisasi, objektivasi dan internalisasi. Akibat bullying termasuk dalam momen eksternalisasi yang artinya sebagian besar korban selalu memikirkan tindakan bullying dan sulit untuk mencegah terjadinya bullying. Pada momen objektivasi, korban merasakan hasil yang diperoleh dari tindakan bullying yang berupa kesulitan dalam melaksanakan aktivitas belajar. Pada momen internalisasi, korban merasa sadar bahwa bullying telah terjadi pada dirinya.

Berdasarkan hasil penelitian, tindakan bullying tidak hanya dapat mempersulit aktivitas belajar korban, namun juga dapat memberikan dampak positif. Hasil penelitian menunjukkan bahwa salah satu korban bullying merasakan dampak positif bullying, seperti lebih aktif dalam melakukan pembelajaran karena memiliki rasa percaya diri yang tinggi.

\subsection{Konstruksi Sosial Guru: Memberikan Intervensi Terhadap School Bullying}

Bullying dapat dikatan suatu permasalahan yang harus diperhatikan oleh semua pihak di sekolah. Selama ini tidak ada peraturan sekolah yang membatasi perilaku bullying seharusnya sekolah memiliki kebijakan program anti bullying, akan tetapi dalam UndangUndang Nomor 23 Tahun 2002 Pasal 54 tentang perlindungan anak dinyatakan bahwa "keberadaan anak baik di lingkungan sekolah atupun di luar lingkungan sekolah wajib dilindungi dari tindakan kekerasan (fisik/mental) yang dilakukan oleh guru, pengelola sekolah atau teman-temannya atau lembaga pendidikan lainnya". Oleh karena itu, siswa memiliki hak untuk mendapatkan pendidikan di dalam lingkungan sekolah yang aman dan nyaman.

Guru BK di SMP Negeri 10 Malang telah memberikan solusi untuk mencegah terjadinya bullying. Solusi tersebut antara lain dengan memberikan materi mengenai bullying di dalam kelas, meluangkan waktu untuk mendengarkan masalah siswa, memberikan kebebasan pada siswa untuk berkreasi dan menghargai siswa sesuai dengan mengembangkan talenta yang dimiliki. Selain itu, guru BK juga membuat gambar mengenai larangan bullying yang ditempelkan di mading ruangan BK agar siswa dapat lebih memahami mengenai bullying.

Beberapa guru lainnya turut berusaha membuat suasana kelas yang nyaman dengan memberikan ice breaking, membuat media pembelajaran diskusi kelompok, menarik, 
membuat game dan mengadakan kerja bakti. Hal ini bertujuan agar tercipta kelas yang nyaman dan damai. Pihak sekolah juga mengadakan kegiatan IMTAQ yang dilakukan setiap pagi sebelum pembelajaran, kegiatan ini salah satunya dengan memberikan ceramah tentang bullying.

Berdasarkan temuan penelitian, ternyata beberapa cara tersebut belum maksimal hasilnya, karena masih banyak pelaku yang tetap melakukan bullying. Tindakan intervensi yang dilakukan terhadap bullying sangat terbatas, karena tidak semua guru memiliki inisiatif untuk mencegah terjadinya bullying. Bullying sering kali diabaikan dan dianggap sebagai suatu permainan yang wajar di lingkungan sekolah. (Soedjatmiko, 2013) menyatakan bahwa banyaknya pemikiran guru menganggap bullying merupakan bukan rahasia umum yang terjadi di dalam interaksi antar anak bermain dan menganggap salah satu bagian dari proses pendewasaan seorang anak.

Teori konstruksi sosial mengenai intervensi guru terdapat dalam momen eksternalisasi, objektivasi dan internalisasi. Pada momen eksternalisasi adalah usaha guru saat siswanya mendapat perlakuan bullying. Pada momen objektivasi guru akan mendapatkan hasil yang telah dicapai dari usahanya. Berdasarkan hasil penelitian, usaha guru masih belum maksimal terlaksana. Hal ini membutuhkan waktu yang lama, sehingga sebagian guru akan terusmenerus melakukan tindakan intervensi karena sadar bahwa siswa perlu mendapatkan bantuannya, dan hal ini termasuk dalam momen internalisasi.

\section{Simpulan}

\subsection{Kesimpulan}

Bullying di SMP Negeri 10 Malang paling banyak terjadi pada kelas VII yang rata-rata siswanya berusia 13 tahun. Korban bullying di kelas VII berbeda dengan siswa pada umumnya baik secara fisik maupun akademik, korban bullying pernah menyakiti perasaan temannya dan tidak memiliki teman yang banyak.

Bentuk bullying terdiri dari fisik, verbal, mental/psikologis dan elektronik. Bullying verbal merupakan bentuk bullying yang paling sering terjadi di kelas VII. Bullying verbal dapat berpengaruh terhadap psikologis korban seperti memanggil nama orang tua korban yang sudah meninggal. Bullying verbal dapat dilakukan melalui alat elektronik seperti telepon atau biasa disebut bullying elektronik (cyber bullying). Bullying fisik di kelas VII berupa pelecehan seksual secara fisik seperti memegang area sensitif.

Tindakan bullying tidak dapat dilepaskan dari konstruksi sosial karena pelaku, penonton dan guru membenarkan bahwa bullying terjadi karena kesalahan korban itu sendiri. Korban akan merasa terpojok dan tidak dapat membela dirinya sendiri. Hal ini membuat korban menerima tindakan bullying.

Bullying dapat memberikan dampak negatif lebih banyak terhadap korbannya. Contohnya adalah mengalami kesulitan dalam melakukan aktivitas belajar. Meskipun demikian, bullying juga dapat berpengaruh positif seperti menambah semangat belajar, namun hanya satu siswa saja yang mengalaminya,

Tindakan intervensi yang dilakuakan guru adalah memberikan materi mengenai bullying, membuat suasana kelas nyaman dengan cara memberikan ice breaking, membuat media 
pembelajaran menarik dan diskusi kelompok.Tindakan intervensi lainnya adalah diadakannya kegiatan IMTAQ dengan memberikan ceramah tentang bullying. Namun tindakan tersebut masih belum efektif karena masih banyak pelaku yang melakukan bullying.

\subsection{Saran}

Berdasarkan kesimpulan di atas, maka Peneliti menyarankan rumusan yang perlu diajukan sebagai berikut. Kepala sekolah dan guru SMP Negeri 10 Malang hendaknya tidak bersikap kasar yang dapat menimbulkan siswa mencontoh perbuatannya. Bagi siswa korban bullying disarankan untuk melawan tindakan pelaku, sehingga pelaku dapat merasa kalah dengan korban. Siswa korban bullying hendaknya menunjukkan bakat yang lebih hebat kepada pelaku. Bagi petugas keamanan diharapkan untuk berkeliling kelas yang rawan terjadi tindakan bullying. Bagi orang tua siswa hendaknya menjadi teladan yang baik bagi anak, agar anak dapat meniru tindakan orang tua. Bagi penindaklanjut berikutnya peneliti disarankan untuk meneliti faktor yang melatar belakangi pelaku bullying melakukan bullying, dampak yang dialami pelaku bullying setelah melakukan bullying dan solusi yang efektif untuk mengatasi school bullying.

\section{Daftar Rujukan}

Aryanto, A. (1992). Tinjauan Teori Reasoned Action dan Planned Behavior Mengenai Tingkah Laku Terlibat dalam Perkelahian pada Siswa SLTA dan STM di Jakarta. Jakarta: Psikologi UI.

Astuti, P. R. (2008). Meredam Bullying 3 Cara Efektif Meredam K.P.A (Kekerasan Pada Anak). Jakarta: Grasindo.

Coloroso, B. (2007). Stop Bullying!. Jakarta: PT Serambi Ilmu Semesta.

Ehan. (2012). Bullying dalam Pendidikan. Journal Psikologi, 11(1):5,.

Gerungan. (1991). Psikologi Sosial. Bandung: PT Eresco.

Idrus \& Ishak. (1996). Analisis Hasil Belajar. Padang: Kanwil Depdikbud rog. Sumatera Barat.

Kamus Besar Bahasa Indonesia (KBBI), Online (http://kbbi.web.id/). (n.d.).

Lahey, B. B. (2009). Psychology: An Introduction. New York: McGraw Hill Companies, Inc.

Mappiare, A. (1982). Psikologi Remaja. Surabaya: Usaha Nasional.

Miles, Mettew B. \& Huberman, A., Michael. (1992). Analisis Data Kualitatif (Buku Sumber Tentang MetodeMetode Baru). Terjemahan Tjetjep Rohendi Rohidi. Jakarta: UI Press.

Mudjijanti, F. (2011). School Bullying dan Peran Guru dalam Mengatasinya. Naskah Krida Rakyat. Retrieved from Naskah Krida Rakyat: (Online), (http://www.download.portalgaruda.org), diakses 20 Maret 2017.

Olweus, D. (2003). Bullying at School. UK: Blackwell Publishers.

Peter L Berger \& Luckmann, Thomas. (1990). Tafsir Sosial atas Kenyataan Risalah tentang Sosiologi Pengetahuan. Jakarta: LP3ES.

Riauskina, I.I., Djuwita, R., dan Soesetio, S.R. (2005). Gencet-Gencetan dimata Siswa/Siswi Kelas 1 SMA: Naskah Kognitif tentang Arti, Scenario, dan Dampak Gencet-Gencetan. Jurnal Psikologi Sosial, (Online), 12(01), 1-13.

Rigby, K. (2003). Consequences of Bullying in Schools. Canadian Journal of Psychiatry, (Online), 48: 583-590, (http://www.kenrigby.net), diakses 12 Maret 2016.

SEJIWA. (2008). Bullying Mengatasi Kekerasan di Sekolah dan Lingkungan Sekitar Sekolah. Jakarta: PT Grasindo.

Septrina, Mega \& Liow, Cherly. (2009). Hubungan Tindakan Bullying di Sekolah dengan Self Esteem Siswa. Journal Psikologi, (Online), 3:101,(http://www.repository.gunadarma.ac.id), diakses 5 Mei 2017.

Soedjatmiko. (2013). Gambaran Bullying dan Hubungannya dengan Masalah Emosi dan Perilaku pada Anak Sekolah Dasar. Jurnal Sari Pediatri, (Online), 15(3):5, (http://www/saripediatri.idai.or.id), diakses 5 Mei 2017. 
Jurnal Integrasi dan Harmoni Inovatif Ilmu-Ilmu Sosial (JIHI3S), 1(2), 2021, 173-181

Tisna, R. (2010). Informasi Perihal Bullying: Indonesia Anti Bullying. Retrieved from Wordpress: (Online), (http://bigloveadagio.files.wordpress.com). Diakses 18 Desember 2016.

Undang-Undang Nomor 23 Tahun 2002 Pasal 54. (2002). tentang perlindungan anak. Jakarta: Depdiknas.

Wiyani, N. A. (2012). Save Our Children from School Bullying. Jogjakarta: AR-Ruzz Media. 